\title{
Rare earth element analysis of UR CAIs in CV3 chondrites by SRXRF
}

P.-T. GENZEL ${ }^{1 *}$, B. BAZI ${ }^{2}$, A. N. KROT ${ }^{7}$, E. DE PAUW ${ }^{2}$, B. VEKEMANS ${ }^{2}$, M. A. IVANOVA ${ }^{4}$, C. MA ${ }^{5}$, A. M. DAVIS ${ }^{6}$, M. LINDNER ${ }^{1}$, J. GARREVOET $^{3}$, G. FALKENBERG ${ }^{3}$, L. VINCZE ${ }^{2}$, F. E. BRENKER ${ }^{1,7}$

${ }^{1}$ Goethe University Frankfurt, Institute of Geoscience, Frankfurt, Germany (*correspondence:

Genzel@em.uni-frankfurt.de), ${ }^{2}$ Department of

Chemistry, Ghent University, Ghent, Belgium, ${ }^{3}$ PETRA III, DESY, Hamburg, Germany, ${ }^{4}$ Vernadsky Institute, Moscow, Russia, ${ }^{5}$ California Institute of Technology, Pasadena, USA, ${ }^{6}$ University of Chicago, USA, ${ }^{7} \mathrm{HIGP}$, University of Hawai'i at Mānoa, Honolulu, USA

$\mathrm{Ca}, \mathrm{Al}$-rich inclusions (CAIs) are characterized by volatility-fractionated rare earth element (REE) patterns (group I-VI) [e.g., 1,2]. CAIs with group II REEs are depleted in the most refractory [ultrarefractory (UR)] REEs and enriched in the less refractory REEs. The group II REEs resulted from condensation in a gaseous reservoir from which UR REEs were removed either by condensation or incomplete evaporation [3]. Little known about the specific mineral carriers of UR REEs. Therefore, CAIs with UR REE patterns, complementary to those with group II REEs, could provide important information on these carriers [4-7].

Here we report on REE patterns in individual minerals of three CV CAIs containing abundant very refractory $\mathrm{Zr}, \mathrm{Sc}, \mathrm{Y}$-rich oxides and silicates, $A l-2,33 E$ 1 , and $3 N-24[9,10]$, measured with synchrotron radiation X-ray fluorescence spectrometry (SRXRF). The REE patterns in these CAIs have a strong UR trend for all measured phases, with heavy REEs strongly enriched over light REEs. Unique carrier phases of UR patterns were not identified, but are presumed to be $\mathrm{Zr}, \mathrm{Sc}, \mathrm{Y}$-rich minerals. As consequence we infer that all constituents of single UR CAIs originate in the same solar nebula region possibly by condensation.

[1] Mason B. and Martin P. M. (1977) Smithson. Contrib. Earth Sci. 19:84-95. [2] MacPherson G.J. (2014) Treatise Geochem. 2:139-179. [3] Hu J.Y. et al. (2020) Lunar Planet. Sci. 51:1631. [4] Davis A. M. and Grossman L. (1979) Geochim. Cosmochim. Acta 43:1611-1632. [5] Davis A.M. (1991) Meteoritics 26:330. [6] Hiyagon H. et al. (2003) Lunar Planet. Sci. 34:1552. [7] Uchiyama K. et al. (2008) Lunar Planet. Sci. 39:1519. [8] Ivanova M.A. et al. (2012) Meteorit. Planet. Sci. 47:2107-2127. [9] Krot A.N. et al. (2019) Geochemistry 79:125519. 